\title{
Primeiro registro de ácaros eriofiídeos (Acari, Eriophyidae) em seringueiras (Hevea brasiliensis Muell. Arg., Euphorbiaceae) da Floresta Amazônica, Brasil ${ }^{1}$
}

\author{
Reinaldo J.F. Feres ${ }^{2}$
}

\begin{abstract}
First record of eriophyid mites (Acari, Eriophyidae) from rubber trees in the Amazonian Forest, Brazil. Calacarus heveae Feres, 1992 was the first eriophyid mite reported from Hevea brasiliensis Muell. Arg. This mite was first found in northwestern São Paulo State, Brazil. FERES (1998) described two additional species, Shevtchenkella petiolula and Phyllocoptruta seringueirae, from the same host and from same region. The commercial monocultural planting of the Amazonian rubber tree in the northwestern region of São Paulo State started about 18 years ago. In the Amazonian region, the native rubber tree grows dispersed between other plant species. Until now these eriophyids have been collected only on monocultural plantings. This paper reports the occurrence of $C$. heveae, $S$. petiolula and $P$. seringueirae on H. brasiliensis in the Amazonian Forest for the first time. The monocultural method in association with prevailing climatic conditions allows periodic outbreaks of these mites is believed. These new records for those three eriophyid species on rubber trees growing in natural conditions corroborate this hypothesis.

KEY WORDS. Acari, Eriophyidae, Hevea brasiliensis, rubber tree, Brasilian Amazonia
\end{abstract}

Na Amazônia, as seringueiras se desenvolvem isoladamente, separadas por barreiras compostas por várias outras espécies de plantas. A implantação da heveacultura em vários Estados do Brasil, associada a fatores climáticos das novas regiões em que foram introduzidas, tem propiciado a associação de várias espécies de ácaros com essas plantas (FERES 2000).

Na região noroeste do Estado de São Paulo, o plantio de seringueiras em regime de monocultura iniciou-se há cerca de 18 anos e vem passando por grande expansão. Somente na região de São José do Rio Preto, que abrange 23 municípios, esse plantio ocupa cerca de 8.300 hectares, com mais de 3.870 .000 pés plantados. O primeiro registro de ácaro eriofiídeo sobre Hevea brasiliensis Muell. Arg. foi o de Calacarus heveae Feres, 1992, ocorrendo em seringueiras dessa região. FERES (1998) descreveu mais duas espécies, Shevtchenkella petiolula e Phyllocoptruta seringueirae, coletadas sobre esse mesmo hospedeiro e na mesma região.

1) Parte do Programa BIOTAFAPESP - O Instituto Virtual da Biodiversidade.

Home page: http://www. biotasp.org.br

2) Departamento de Zoologia e Botânica, Universidade Estadual Paulista. Rua Cristóvão Colombo 2265, Jardim Nazareth, 15054-000 São José do Rio Preto, São Paulo, Brasil. E-mail: reinaldo@zoo.ibilce.unesp.br 
Com o registro de $C$. heveae e, posteriormente, de S. petiolula e P. seringueirae, em áreas de cultivo de seringueiras nos Estados de São Paulo, Mato Grosso, Mato Grosso do Sul, Minas Gerais e Goiás, foram levantadas questões, até o momento não esclarecidas: qual a origem desses eriofiídeos? Estariam estas espécies já presentes em plantas nativas desses Estados, e se adaptando à nova cultura? FERES (1992) sugeriu a hipótese de que $C$. heveae seria originária da região amazônica, alcançando altos níveis populacionais apenas nas regiões em que a cultura foi introduzida, em associação às novas condições climáticas dessas regiões.

Com o objetivo de investigar essas questões providenciou-se a coleta, em 20 de outubro de 2000, de folhas de seringueiras de uma área de floresta tropical de terra firme pertencente a "Reserva do Km 41" (59 $\left.48^{\prime} \mathrm{W}, 2^{\circ} 25^{\prime} \mathrm{S}\right)$, do Projeto de Dinâmica Biológica de Fragmentos Florestais (Instituto Nacional de Pesquisa da Amazônia -Smithsonian Institution), distante cerca de $80 \mathrm{~km}$ de Manaus, Amazonas, Brasil. Essa reserva compreende uma área de mata contínua, com dossel de altura entre $30-40 \mathrm{~m}$. Quarenta folíolos foram coletados aleatoriamente de quatro árvores, sendo três delas com altura em torno de $2 \mathrm{~m}$ e uma com cerca de $4 \mathrm{~m}$. Todos os eriofiídeos presentes nos 40 folíolos foram montados em lâminas de microscopia.

A análise do material revelou a presença de exemplares das três espécies de Eriophyidae já descritas e de duas novas espécies que deverão ser descritas oportunamente. No total, foram registrados 318 ácaros eriofí́deos (7,9 indivíduos/folíolo) nas seguintes proporções $(\mathrm{F}=$ fêmea, $\mathrm{M}=$ macho, $\mathrm{N}=$ ninfa): $P$. seringueirae, 249 indivíduos (159F, 69M, $21 \mathrm{~N}$ ), 6,2 indivíduos/folíolo; $S$. petiolula, 63 indivíduos (46F, 14M, 3N), 1,6 indivíduo/folíolo; C. heveae, 3F, 0,07 indivíduo/folíolo; mais três exemplares fêmeas de duas novas espécies. Na região noroeste de São Paulo temos registros de até 530 indivíduos de $C$. heveae em um só folíolo (trabalho em preparação). Essa espécie é considerada séria praga das seringueiras cultivadas.

Os três exemplares de $C$. heveae coletados apresentam secreção cerosa muito reduzida na região do escudo dorsal e praticamente nenhuma sobre as três elevações longitudinais dorsais do opistossoma, ao contrário dos exemplares registrados nos Estados em que $H$. brasiliensis foi introduzida. O aumento da secreção cerosa pode ser uma característica adaptativa a regiões de clima seco.

Esses dados reforçam a hipótese anteriormente aventada, que essa espécie estaria originalmente associada às seringueiras nativas (FERES 1992), sofrendo incremento populacional nas seringueiras introduzidas e cultivadas em regime de monocultura em regiões de clima mais seco que o da Amazônia. Além disso, coletas efetuadas em euforbiáceas nativas na região noroeste do Estado de São Paulo (trabalho em preparação) não acusaram a presença de nenhuma das espécies de eriofiídeos registradas em seringueira.

Embora se trate de uma amostragem pontual, os resultados são significativos já que se registra pela primeira vez em seringueiras da floresta amazônica a ocorrência das três espécies de eriofí́deos descritas de seringueiras cultivadas.

Os exemplares coletados estão depositados na coleção científica de Acari (DZSJRP), do Departamento de Zoologia e Botânica, Universidade Estadual Paulista (UNESP), São José do Rio Preto, São Paulo, Brasil.

Revta bras. Zool. 18 (Supl. 1): 343 - 345, 2001 
AGRADECIMENTOS. Ao Biólogo Thiago J. Izzo, pós-graduando do INPA, Manaus, Amazonas, pela realização da coleta e envio do material, bem como pelas informações fornecidas a respeito da área de coleta e das plantas amostradas. Aos Profs. Drs. Francisco Langeani Neto e Denise de C. Rossa Feres, Depto. de Zoologia e Botânica, IBILCE-UNESP, São José do Rio Preto, SP., pela leitura crítica do manuscrito e sugestões apresentadas. Este trabalho é o de $n^{\circ}$ 340 da série técnica de publicações do Projeto "Dinâmica Biológica de Fragmentos Florestais"Convênio de cooperação cientifica entre o Instituto Nacional de Pesquisas da Amazônia e o Smithsonian Institution dos EUA.

\section{REFERÊNCIAS BIBLIOGRÁFICAS}

FERES, R.J.F. 1992. A new species of Calacarus Keifer (Acari, Eriophyidae, Phyllocoptinae) from Hevea brasiliensis Muell. Arg. (Euphorbiaceae) from Brazil. Internat. Jour. Acarol. 18 (1): 61-65. . 1998. Two new Phyllocoptine mites (Acari:Eriophyidae) from Hevea brasiliensis Muell. Arg. (Euphorbiaceae) from Brazil. Internat. Jour. Acarol. 24 (1): 69-74.

. 2000. Levantamento e observações naturalísticas da acarofauna (Acari, Arachnida) de seringueiras cultivadas (Hevea spp., Euphorbiaceae) no Brasil. Revta bras. Zool. 17 (1): 157-173.

Recebido em 15.XII.2000; aceito em 29.VI.2001. 